\title{
PENGARUH PRIVACY, SOCIAL INFLUENCE TERHADAP ONLINE PURCHASE INTENTION: TRUST SEBAGAI VARIABEL MEDIASI
}

\author{
Veronica1, Rodhiah" \\ ${ }^{1}$ Program Studi Manajemen Fakultas Ekonomi dan Bisnis, Universitas Tarumanagara \\ Email:veronicawu70@gmail.com \\ ${ }^{2}$ Program Studi Manajemen Fakultas Ekonomi dan Bisnis, Universitas Tarumanagara \\ *Email: rodhiah@fe.untar.ac.id \\ *penulis korespondensi
}

Masuk : 23-10-2020, revisi: 13-03-2021, diterima untuk diterbitkan : 15-03-2021

\begin{abstract}
ABSTRAK
Tujuan penelitian ini adalah untuk mengetahui pengaruh privacy, social influence terhadap online purchase intention dan trust sebagai variabel mediasi. Desain penelitian yang digunakan adalah metode kuantitatif dengan pendekatan deskriptif. Pengambilan sampel menggunakan metode nonprobability sampling dengan teknik purposive sampling. Sampel pada penelitian ini sebanyak 100 responden. Pengumpulan data dilakukan dengan cara menyebarkan kuesioner melalui link google form. Analisis data menggunakanPartial Least Squares- Structural Equation Modelling (PLS- SEM) dengan menggunakan software SmartPLS versi 3.0. Hasil penelitian menunjukan bahwa privacy dan social influence mempengaruhi online purchase intention secara positif dan signifikan. Trust dapat memediasi privacy terhadap online purchase intention secara positif dan signifikan pada pelanggan Shopee di Jakarta. Hasil penelitian ini memberikan penjelasan kepada pelanggan Shopee bahwa hal terpenting dalam berbelanja secara online adalah keamanan yang ketat sehingga meningkatkan rasa kepercayaan dan feedback berupa kepuasan dan ketidakpuasan terhadap produk yang telah dibeli.
\end{abstract}

Kata Kunci: Privacy, Trust, Online Purchase Intention

\begin{abstract}
The purpose of this research is to investigate the effect of privacy, social influence on online purchase intention and trust as a mediation. The research design used is a qualitative method with a descriptive approach. This research uses non probability sampling method with purposive sampling technique. The sample number is 100 respondents.Data collection is done by distributing questionnaires through the google form link. Partial Least Squares- Structural Equation Modelling (PLS-SEM) is used to analyze research data by using SmartPLS ver 3.0. The findings show privacy and social influence possitively and significanly on online purchase intention. Trust can mediate privacy of online purchase intention on Shopee customers at Jakarta.The results of this research provide an explanation to Shopee customers that the important thing in online purchasing is tight security increasing trust and feedback as satisfaction and dissatisfaction with the product that has been purchased.
\end{abstract}

Keywords: Privacy, Trust, Online Purchase Intention

\section{PENDAHULUAN}

\section{Latar Belakang}

Pada zaman globalisasi saat ini, hampir semua orang sudah memiliki handphone atau barang elektronik yang lainnya untuk bisa mengakses e-Commerce. Melalui akses tersebut dengan mudah dapat berbelanja secara online, tidak perlu datang ke toko offline. Pembelanja secara online termotivasi untuk berbelanja melalui internet karena kemudahan, kenyamanan, Privacy dan ketersediaan segala produk. Banyak konsumen membeli secara online jika metode pembayaran elektronik aman dan privasi informasi pribadi mereka dilindungi. Namun informasi yang bisnis kumpulkan dapat disalahgunakan oleh pengguna resmi dan tidak sah. Hal ini meningkatkan kekhawatiran konsumen yang memiliki niat pembelian secara online.

Kekhawatiran terbesar pada pembelajaan secara online adalah masalah privasi yang tidak dilindungi, dibandingkan masalah-masalah lainnya seperti, menjual barang palsu, produk yang 
tidak memenuhi standar, dan lainnya. Hal yang harus disiapkan adalah privacy yang ketat dalam bertransaksi, identitas pelanggan, dan lainnya aman, sehingga pelanggan merasa adanya privacy pada marketplace yang sudah dipilih. Melalui privacy tersebut akan membangun rasa percaya (trust) pada pelanggan yang ingin berbelanja secara online Chen et al., (2015). Bianchi \& Andrews, (2012) mengemukakan bahwa dengan adanya kepercayaan maka akan memberikan rasa kenyamanan bagi konsumen dalam berbagi informasi saat melakukan pembelian berdasarkan pada saran-saran. Sehingga dengan semakin tingginya nilai kepercayaan terhadap suatu merek maka akan membuat kita semakin yakin untuk melakukan pembelian pada produk tersebut tanpa adanya rasa ragu.

Clemons et al., 2016 meneliti bahwa semakin pelanggan percaya (trust) dengan suatu marketplace, maka dapat adanya peningkatan pada pembelanjaan secara online. Selain itu setelah berbelanja secara online, konsumen akan memberi informasi kepada calon pelanggan dengan cara memberikan komentar produk yang mereka terima sehingga menimbulkan jejaring sosial (social influence). Menurut Siedlecki et al. (2014) bahwa bimbingan, saran, dan informasi dari kelompok sosial dapat membantu menyelesaikan masalah keputusan pembelian barang secara online, dukungannya dalam bentuk informasi yang bermanfaat meningkatkan rasa kebahagiaan seseorang.

Jejaring sosial terjadi secara alami bisa berupa review produk atau jasa (e-wom) yang konsumen dapatkan dari suatu marketplace. Menurut Amin (2007) pelanggan memiliki kecenderungan untuk menyelaraskan harapan Nya sangat penting dan meminta persetujuan lingkungan sosial agar produk yang tersedia di marketplace diterima oleh masyarakat. Terdapat banyak marketplace di Indonesia seperti Shopee, Tokopedia, Bukalapak, Lazada, dan lainnya, penelitian ini akan membahas tentang market place Shopee, yang menjual segala kebutuhan rumah tangga, alat- alat elektronik, produk digital. Keamanan Shopee sudah terjaga, dari segi informasi data diri maupun informasi transaksi yang konsumen lakukan di Shopee, tetapi tetap saja terdapat masalah kebobolan pada privacy data pelanggan. Hal tersebut dapat mempengaruhi kepercayaan (trust) pada pelanggan yang akan melakukan pembelian secara online (online purchase intention) dan menurunkan jaringan social.

Jaringan sosial memiliki waspada saat ingin berbelanja secara online di Shopee. Penggunaan Shopee melibatkan berbagi pengguna sehingga menghasilkan informasi di jaringan sosial atau komunitas sosial dari pengguna. Dengan demikian, Social Influence mempengaruhi penilaian atau pendapat konsumen yang berpengaruh pada, pengambilan keputusan pembelian secara online. Niat belanja konsumen melalui pendapat dari rekan- rekan pelanggan yang pernah berbelanja atau Review dari konsumen yang berbelanja di Shopee. Pada Shopee juga terdapat fitur untuk menilai kepuasan pelanggan sebagai social influence, penilaian konsumen tersebut sangatlah berpengaruh pada penjualan di Shopee, jika penilaian buruk maka penjualan akan menurun, sebaliknya jika penilaian bagus maka penjualan akan meningkat.

Untuk itu penelitian ini bertujuan untuk mengetahui pengaruh dari privacy, social influence terhadap online purchase intention dengan trust sebagai variabel mediasi pada konsumen Shopee.

\section{KAJIAN PUSTAKA}

Definisi Variabel

Privacy. Chiu (2009) menyatakan bahwa privacy adalah kemampuan suatu situs web perbelanjaan online menjaga dan melindungi informasi baik data diri, alamat, proses transaksi 
yang dimiliki oleh pelanggan. Han and Maclaurin (2002) Privacy dipersepsikan tidak aman oleh pelanggan yang kurang paham tentang teknologi, jika pelanggan yang paham dengan teknologi maka privacy akan aman- aman saja karna pelanggan mengetahui cara menanggulangi masalah privacy.

Social Influence.Venkatesh et al., (2003) menjelaskan bahwa social influence adalah pengaruh dari lingkaran sosial seorang individu penting bagi setiap individu di mana dia melihat dirinya sesuai dengan pengaruh dalam kehidupannya. Delre (2010) social influence adalah faktor yang mengacu emosional melalui pemodelan, ajaran dan bujukan dari lingkungan sekitar.

Trust.Chen (2007)menyatakan bahwa trust adalah hal yang paling sulit untuk dibangun karena kepercayaan dating dari dalam diri pelanggan sendiri, sehingga orang lain tidak bisa mengatur kepercayaan pelanggan. Sedangkan Eisingerich (2007) trust adalah penentu keberhasilan suatu perusahaan, karena jika pelanggan tidak percaya pada perusahaan maka itu akan menimbulkan hal yang negatif bahkan untuk waktu jangka panjang.

\section{Kaitan antar variabel}

Kaitan antara privacy dan trust. Wu (2012) menjelaskan bahwa jika privasi dengan penjagaan yang tinggi maka kepercayaan pelanggan juga tinggi sehingga akan meningkatkan niat beli secara online. Hasil serupa dengan France Belanger (2002), mengemukakan bahwa privacy berpengaruh positif secara signifikan terhadap trust pada mahasiswa US Southeastern University dalam berbelanja secara online. Hal tersebut bersangkutan dengan informasi yang asli pada layanan eCommerce, informasi pelanggan yang terjaga, sehingga mempengaruhi pelanggan percaya pada situs pembelanjaan online

Kaitan antara social influence dan online purchase intention. Bertrandias (2014) menjelaskan bahwa jejaring sosial yang baik maka akan berpengaruh positif bagi pembelian secara online, dan Sesuai dengan penelitian sebelumnya Rosetta (2014) dan Husnain (2017) mengemukakan bahwa jejaring sosial berpengaruh positif terhadap minat beli secara online. Hal itu bersangkutan dengan konsumen yang telah berbelanja akan terikat dan dekat dengan suatu merk sehingga adanya keterkaitn emosional yang dapat meningkatkan perilaku konsumen dalam berbelanja secara online.

Kaitan antara trust dan online purchase intention. Liu (2017) menjelaskan bahwa terdapat pengaruh positif antara trust dengan online purchse intention. Sedangkan menurut Bianci dan Andrew (2012) mengemukakan bahwa dengan adanya faktor kepercayaan baik dari sisi orang ketiga maupun lingkungan budaya kepercayaan mempunyai penagaruh yang positif terhadap online purchase intention. Hal ini berkaitan dengan adanya nilai sosialisasi individu yang berada di dalam suau negara asalnya sehingga konsumen bertindak sebagai seseorang individu dengan berdasarkan pada nilai budaya negara asal mereka yang mempengaruhi niat pembelian dalam melakukan suatu keputusan.

Online Purchase Intention. Lin (2018) menyatakan bahwa online purchase intention adalah evaluasi produk dan layanan yang dibuat oleh konsumen yang menghasilkan suatu kemungkinan bertransaksi. Poddar (2009) menyatakan online purchase intention adalah menandakan evaluasi parameter penilaian pembeli mengenai karakteristik situs internet, survei pengalaman, pencarian instruksi dan juga analisis pasca pembelian. 
Trust memediasi privacy terhadap online purchase intention. Murkherjee (2007) yang menjelaskan bahwa privasi yang ketat akan menimbulkan peran kepercayaan yang berpengaruh secara positif terhadap pembelian secara online. Sedangkan menurut Eisingerich (2007) kepercayan merupakan penentu keberhasilan suatu perusahaan, karena jika pelanggan tidak percaya pada perusahaan maka itu akan menimbulkan hal yang negatif bahkan untuk waktu jangka panjang, niat pelanggan untuk pembelian secara tidak ada maka semakin lama situs web akan mengalami kerugian karena tidak ada yang membeli.

Berdasarkan uraian kaitan antar variabel di atas, maka model penelitian yang digunakan dalam penelitian ini adalah sebagai berikut.

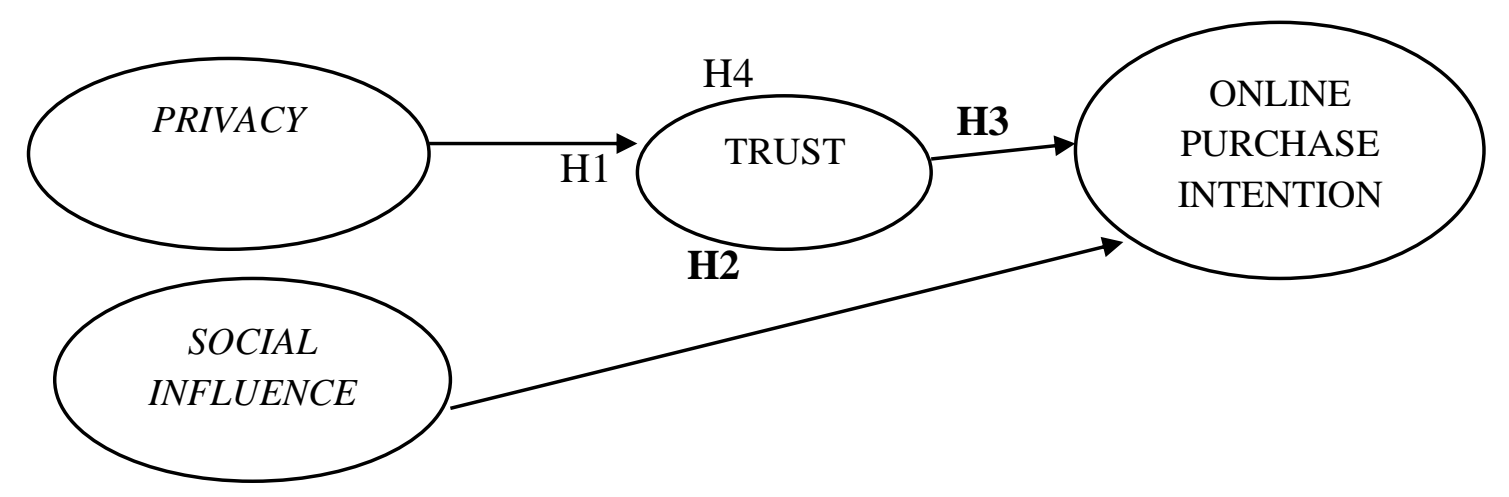

Gambar 1. Model Penelitian

\section{Hipotesis}

H1: Privacy berpengaruh positif dan signifikan terhadap trust pada pelanggan Shopee di Jakarta.

H2: Social Influence berpengaruh positif dan signifikan terhadap online purchase intention pada pelanggan Shopee di Jakarta.

H3: Trust berpengaruh positif dan signifikan terhadap online purchase intention pada pelanggan Shopee di Jakarta.

H4: Trust memediasi privacy secara positif dan signifikan terhadap online purchase intention pada pelanggan Shopee di Jakarta.

\section{METODE PENELITIAN}

Penelitian ini merupakan penelitian deskriptif dengan pendekatan cross sectional.Populasi yang akan dilibatkan yaitu seluruh pengguna aplikasi Shopee dan pernah berbelanja menggunakan Shopee.Pengambilan sampel dengan metode non-probability sampling dengan metode purposive sampling yang berarti pengambilan sampel secara non random sampling dimana peneliti akan menentukan responden yang ingin diteliti karena peneliti menentukan ciri-ciri khusus agar dapat meneliti sesuai tujuan. Penyebarankuesioner dengan menggunakan google form berupa link. Penelitian ini menggunakan sampel sebanyak 100 sampel. Dari jumlah 100 responden yang digunakan dalam penelitian ini , mayoritas responden berjenis kelamin wanita (81\%) dan pria (19\%), memiliki pendidikan terakhir SMA/SMK (64\%), berusia di antara 18-23 tahun $(81 \%)$ dan mayoritas responden seorang pelajar/ mahasiswa $(65 \%)$. Berikut indikator yang digunakan dalam pengukuran variabel pada Tabel 1. 
Tabel 1. Indikator Pengukuran Variabel

\begin{tabular}{|c|c|c|}
\hline Variabel & Indikator & Sumber \\
\hline Privacy & $\begin{array}{l}\text { 1. eCommerce meminta informasi pribadi } \\
\text { yang relevan } \\
\text { 2. eCommerce tidak menyalahgunakan } \\
\text { privasi pelanggan untuk tujuan lain } \\
\text { 3. Pernyataan kebijakan privasi itu penting } \\
\text { dalam keputusan pelanggan untuk } \\
\text { membeli di eCommerce } \\
\text { 4. Banyak informasi yang dikumpulkan e- } \\
\text { Commerce }\end{array}$ & $\begin{array}{l}\text { Chen, Y.-H. and } \\
\text { Barnes, S. } \\
(2007)\end{array}$ \\
\hline Social Influence & $\begin{array}{l}\text { 1. Berbagi pengalaman tentang berbelanja di } \\
\text { eCommerce dengan teman sebaya } \\
\text { 2. Informasi tentang eCommerce berasal } \\
\text { dari teman dan keluarga } \\
\text { 3. Lingkungan sekitar merekomendasikan } \\
\text { eCommerce tertentu } \\
\text { 4. Mencari informasi eCommerce dengan } \\
\text { lingkungan sekitar } \\
\text { 5. Sering mengajak teman untuk berbelanja } \\
\text { di eCommerce }\end{array}$ & $\begin{array}{l}\text { Delre, S.A., } \\
\text { Jager, W., } \\
\text { Bijmolt, T.H. } \\
\text { and Janssen, } \\
\text { M.A. (2010). }\end{array}$ \\
\hline Trust & $\begin{array}{l}\text { 1. eCommerce ini menepati janji dan } \\
\text { kewajibannya } \\
\text { 2. eCommerce ini dapat dipercaya dan } \\
\text { jujur. } \\
\text { 3. eCommerce ini hampir tidak pernah } \\
\text { mengecewakan } \\
\text { 4. Produk yang dijual di eCommerce ini } \\
\text { sesuai dengan harapan }\end{array}$ & $\begin{array}{l}\text { Akroush, } \\
\text { Mamoun N dan } \\
\text { Mutaz M. Al- } \\
\text { Debei. } 2015 .\end{array}$ \\
\hline Online Purchase Intention & $\begin{array}{l}\text { 1. sering berbelanja secara online } \\
\text { 2. Kemudahan dalam berbelanja secara } \\
\text { online } \\
\text { 3. Banyak promo menarik di eCommerce } \\
\text { 4. Berkomunikasi dengan penjual di } \\
\text { eCommerce ini mudah } \\
\text { 5. Kemudahan mencari suatu produk di } \\
\text { eCommerce }\end{array}$ & $\begin{array}{l}\text { Delia, Vazquez., } \\
\text { Xingang Xu., } \\
(2009))\end{array}$ \\
\hline
\end{tabular}

\section{HASIL DAN PEMBAHASAN}

\section{Outer Model}

Berdasarkan analisis hasil model pengukuran (Outer Model Analysis) ditemukan bahwa semua indikator yang digunakan untuk mengukur variabel-variabel penelitian bersifat valid dan reliable sehingga dapat merepresentasikan variabel-variabel penelitian dan dapat dipercaya dan diandalkan. 


\section{a. Convergent Validity (Validitas Konvergen)}

Tabel 2. Hasil Analisis Average Variance Extracted (AVE)

\begin{tabular}{cc}
\hline Variabel/Dimensi & AVE \\
\hline Online Purchase Intention & 0,74 \\
\hline Privacy & 0,73 \\
\hline Social Influence & 0,67 \\
\hline Trust & 0,71 \\
\hline
\end{tabular}

Diketahui bahwa nilai AVE dari masing masing variabel memiliki nilai diatas 0,5 yang telah memenuhi kriteria convergent validity yang diukur dari nilai AVE. Hal ini menunjukkan bahwa variabel-variabel pada penelitian ini telah memenuhi.

Tabel 3. Hasil Analisis Loading Factor

\begin{tabular}{|c|c|c|c|c|}
\hline Indikator & OPI & $\mathbf{P}$ & SI & $\mathbf{T}$ \\
\hline OPI1 & 0,858 & & & \\
\hline OPI2 & 0,900 & & & \\
\hline OPI3 & 0,820 & & & \\
\hline OPI4 & 0,683 & & & \\
\hline OPI5 & 0,829 & & & \\
\hline $\mathrm{P} 1$ & & 0,780 & & \\
\hline $\mathrm{P} 2$ & & 0,890 & & \\
\hline P3 & & 0,845 & & \\
\hline $\mathrm{P} 4$ & & 0,901 & & \\
\hline SI1 & & & 0,763 & \\
\hline SI2 & & & 0,876 & \\
\hline SI3 & & & 0,923 & \\
\hline SI4 & & & 0,709 & \\
\hline SI5 & & & 0,815 & \\
\hline $\mathrm{T} 1$ & & & & 0,891 \\
\hline $\mathrm{T} 2$ & & & & 0,916 \\
\hline $\mathrm{T} 3$ & & & & 0,762 \\
\hline $\mathrm{T} 4$ & & & & 0,793 \\
\hline
\end{tabular}

Berdasarkan tabel di atas, hasil OPI, P, SI, T memiliki nilai loading factor lebih dari 0,7 , sehingga memenuhi batas minimal dalam analisis convergent validity, tetapi terdapat 1 indikator yang memiliki nilai kurang dari 0,7 yaitu indikator OPI4 sehingga indikator OPI4 akan dihapus. Gambar pada hasil nilai Loading Factor adalah: . 


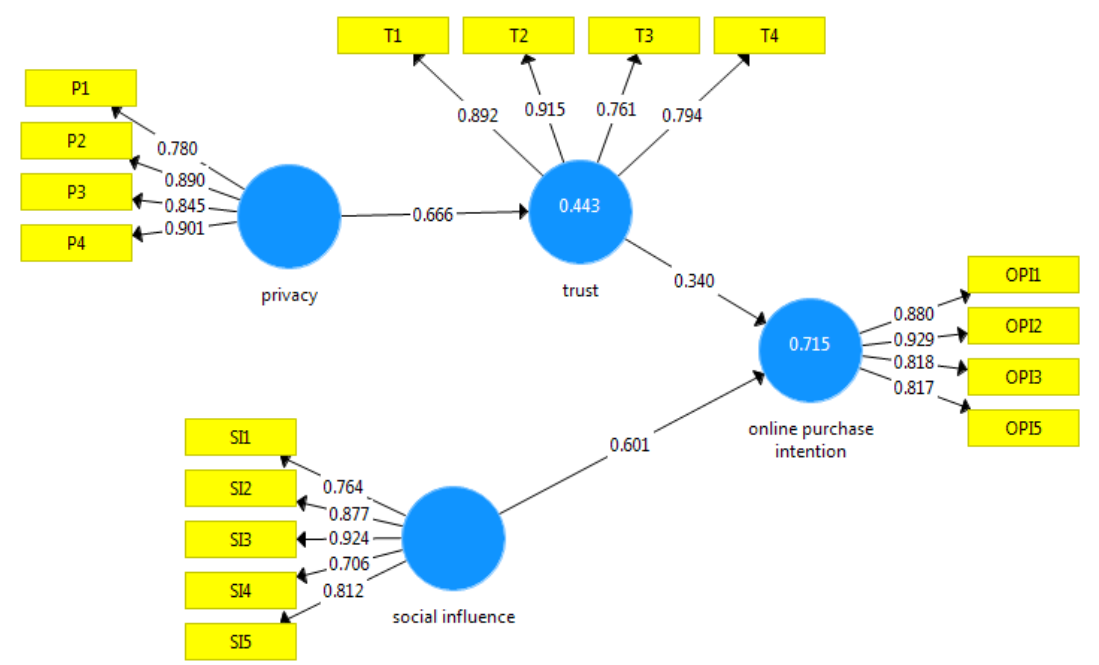

Gambar 2. Hasil Nilai Loading Factor

\section{b. Discriminant Validity}

\begin{tabular}{|c|c|c|c|c|}
\hline Indikator & OPI & $\mathbf{P}$ & SI & $\mathbf{T}$ \\
\hline OPI1 & 0,88 & 0,56 & 0,75 & 0,55 \\
\hline OPI2 & 0,93 & 0,67 & 0,75 & 0,68 \\
\hline OPI3 & 0,82 & 0,52 & 0,60 & 0,58 \\
\hline OPI5 & 0,82 & 0,66 & 0,64 & 0,57 \\
\hline $\mathrm{P} 1$ & 0,55 & 0,78 & 0,59 & 0,55 \\
\hline $\mathrm{P} 2$ & 0,62 & 0,89 & 0,62 & 0,60 \\
\hline P3 & 0,52 & 0,84 & 0,47 & 0,52 \\
\hline $\mathrm{P} 4$ & 0,69 & 0,90 & 0,62 & 0,61 \\
\hline SI1 & 0,69 & 0,52 & 0,76 & 0,58 \\
\hline SI2 & 0,73 & 0,60 & 0,88 & 0,52 \\
\hline SI3 & 0,75 & 0,61 & 0,92 & 0,53 \\
\hline SI4 & 0,45 & 0,45 & 0,71 & 0,33 \\
\hline SI5 & 0,59 & 0,57 & 0,81 & 0,39 \\
\hline $\mathrm{T} 1$ & 0,66 & 0,72 & 0,60 & 0,89 \\
\hline $\mathrm{T} 2$ & 0,60 & 0,65 & 0,52 & 0,92 \\
\hline T3 & 0,41 & 0,34 & 0,27 & 0,76 \\
\hline $\mathrm{T} 4$ & 0,60 & 0,42 & 0,50 & 0,79 \\
\hline
\end{tabular}


Diketahui bahwa nilai loadings dari masing masing indikator setiap variabel lebih besar nilai loadings variabel lainnya. Hal ini menunjukkan bahwa indikator-indikator tersebut telah memenuhi kriteria discriminant validity yang diukur dari nilai cross loadings

\section{Composite Reliability}

Tabel 4. Hasil Analisis Reliabilitas

\begin{tabular}{ccc}
\hline Variabel & Cronbach's Alpha & Composite Reliability \\
\hline Online Purchase Intention & 0,88 & 0,89 \\
\hline Privacy & 0,88 & 0,88 \\
\hline Social Influence & 0,88 & 0,90 \\
\hline Trust & 0,87 & 0,90
\end{tabular}

Composite reliability dari semua variable memiliki nilai Cronbach alpha lebih dari 0,60 dan nilai composite reliability lebih dari 0,70 , dari pernyataan tersebut bisa disimpulkan bahwa masing- masing variabel dapat dinyatakan sebagai variabel yang reliabel.

\section{Koefisien Determinasi $\left(\boldsymbol{R}^{2}\right)$}

Tabel 5. Hasil Uji Koefisien Determinasi $\left(\mathrm{R}^{2}\right)$

\begin{tabular}{lcc}
\hline \multicolumn{1}{c}{ Variabel } & R-Square \\
\hline Online Purchase Intention & 0,71 & \\
\hline Trust & 0,44 & \\
\hline
\end{tabular}

Berdasarkan hasil uji koefisien determinasi nilai R-Square pada variabel online purchase intention sebesar 0,71 yang berarti 71,\% variabel online purchase intention dapat dijelaskan oleh privacy, social influence dan trust, sedangkan sisanya $29 \%$ dijelaskan oleh variabelvariabel lainnya yang tidak termasuk dalam model penelitian. Hasil uji koefisien determinasi pada variabel trust sebesar 0,44 yang berarti $44 \%$ variabel trust dapat dijelaskan oleh variabel privacy, sedangkan sisanya 56\% dijelaskan oleh variabel-variabel lainnya yang tidak termasuk dalam model penelitian.

\section{Path Coefficient}

Menurut Sholiha (2015), bootstrap adalah alat yang digunakan untuk meminimalkan tidak andalnya hubungan dengan kesalahan penggunaan distribusi normal dan penggunanya.

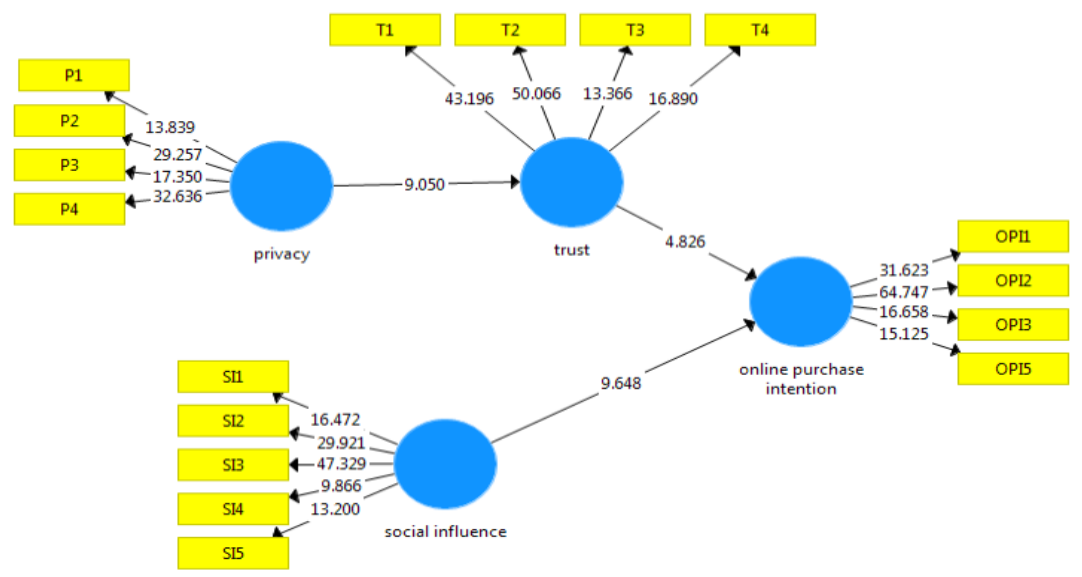

Gambar 3. Hasil Pengujian Bootstrapping 
Dari Gambar 2 dapat dilihat bahwa keseluruhan variabel memiliki path coefficient dengan angka yang positif, yang mengindikasikan bahwa pengaruh antar variabel searah

\section{Uji Hipotesis (Uji t-statistik)}

Tabel 6. Hasil Pengujian Hipotesis

\begin{tabular}{lccc}
\hline \multicolumn{1}{c}{ Variabel } & Original Sample & t-statistics & $\boldsymbol{p}$-values \\
\hline Privacy $\longrightarrow$ Trust & 0,67 & 9,05 & 0,000 \\
\hline $\begin{array}{l}\text { Social Influence } \\
\text { Intention }\end{array}$ & 0,60 & 9,65 & 0,000 \\
\hline Trust $\longrightarrow$ Online Purchase & & & \\
\hline
\end{tabular}

Hasil pengujian variabel privacy terhadap trust memiliki nilai $t$ statistic sebesar 9,05, atau $p$ value sebesar 0,000 yang berarti $\mathrm{H} 1$ tidak ditolak karena $t$ statistic lebih dari 1,96 atau $p$ value kurang dari 0,05 . Jadi, kesimpulannya adalah privacy berpengaruh positif terhadap trust pada pelanggan Shopee di Jakarta secara signifikan.

Hasil pengujian variabel social influence terhadap online purchase intention memiliki $t$ statistic sebesar 9,65, atau $p$ value sebesar 0,000 yang berarti $\mathrm{H} 2$ tidak ditolak karena $t$ statistic lebih dari 1,96 atau $p$ value kurang dari 0,05. Jadi, kesimpulannya adalah social influence berpengaruh positif terhadap online purchase intention pada pelanggan Shopee di Jakarta secara signifikan.

Hasil pengujian variabel trust terhadap online purchase intention memiliki $t$ statistic sebesar 4,83, atau $p$ value sebesar 0,000 yang berarti $\mathrm{H} 3$ tidak ditolak karena $t$ statistic lebih dari 1,96 atau $p$ value kurang dari 0,05 . Jadi, kesimpulannya adalah trustberpengaruh positif terhadap online purchase intention pada pelanggan Shopee di Jakarta secara signifikan.

Tabel 7. Hasil Uji Mediasi

\begin{tabular}{llll}
\hline Variabel & $\begin{array}{c}\text { Indirect } \\
\text { Effect }\end{array}$ & T Statistic & P Value \\
\hline $\begin{array}{l}\text { Privacy } \longrightarrow \text { Trust } \longrightarrow \text { Online } \\
\text { purchase intention }\end{array}$ & 0,23 & 4,34 & 0,000 \\
\hline
\end{tabular}

Berdasarkan hasil pengujian variabel privacy terhadap online purchase intention dengan mediasi trust memiliki $t$ statistic sebesar 4,34 atau $p$ value sebesar 0,000 yang berarti $\mathrm{H} 4$ tidak ditolak karena $t$ statistic lebih dari 1,98 atau $p$ value kurang dari 0,05. Jadi, kesimpulannya adalah trust dapat memediasi privacy secara positif terhadap online purchase intention pada pelanggan Shopee di Jakarta secara signifikan.

\section{Diskusi}

Berdasarkan dari hasil rekapitulasi uji hipotesis, H1 hasilnya tidak ditolak, yang berarti variabel privacy berpengaruh positif secara signifikan terhadap trust. Hasil ini sesuai dengan peneliti yang sebelumnya yang dilakukan oleh Wu et al (2012) yang menjelaskan bahwa jika privasi dengan penjagaan yang tinggi maka kepercayaan pelanggan juga tinggi sehingga akan meningkatkan niat beli secara online. Hasilnya adalah privasi mempengaruhi secara positif terhadap kepercayaan, dan hasil pengujian hipotesis sejalan dengan peneliti sebelumnya yaitu menurut France Belanger, Janine S. Hiller, dan Wanda J. Smith (2002), mengemukakan bahwa privacy berpengaruh positif secara signifikan terhadap trust pada mahasiswa US Southeastern University dalam berbelanja secara online. Hal tersebut bersangkutan dengan informasi yang asli pada layanan eCommerce, informasi pelanggan yang terjaga, sehingga mempengaruhi pelanggan 
percaya pada situs pembelanjaan online. Kemudian hasil rekapitulasi uji hipotesis $\mathrm{H} 2$ hasinya tidak ditolak, yang berarti variabel social influence berpengaruh positif secara signifikan terhadap online purchase intention. Hasil ini sesuai dengan penelitian sebelumnya yang dilakukan oleh Bertrandias and Elgaaied-Gambier (2014) yang menjelaskan bahwa jejaring sosial yang baik maka akan berpengaruh positif bagi pembelian secara online, dan Sesuai dengan penelitian sebelumnya Rosetta (2014) dan Husnain et al., (2017) mengemukakan bahwa jejaring sosial berpengaruh positif terhadap minat beli secara online. Hal itu bersangkutan dengan konsumen yang telah berbelanja akan terikat dan dekat dengan suatu merk sehingga adanya keterkaitn emosional yang dapat meningkatkan perilaku konsumen dalam berbelanja secara online.Hasil rekapitulasi uji hipotesis $\mathrm{H} 3$ hasilnya tidak ditolak yang berarti variabel trust berpengaruh positif dan signifikn terhadap online purchase intention. Hasil ini sejalan dengan Liu, Xiao,Lim (2017) menjelaskan bahwa terdapat pengaruh positif antara trust dengan online purchse intention. Sedangkan menurut Bianchi dan Andrew (2012) mengemukakan bahwa dengan adanya faktor kepercayaan baik dari sisi orang ketiga maupun lingkungan budaya kepercayaan mempunyai penagaruh yang positif terhadap online purchase intention. Hal ini berkaitan dengan adanya nilai sosialisasi individu yang berada di dalam suau negara asalnya sehingga konsumen bertindak sebagai seseorang individu dengan berdasarkan pada nilai budaya negara asal mereka yang mempengaruhi niat pembelian dalam melakukan suatu keputusan.Hasil rekapitulasi uji hipotesis $\mathrm{H} 4$ hasilnya tidak di tolak yang berarti variabel trust dapat memediasi secara positif privacy terhadap online purchase intention. Hasil ini sesuai dengan penelitian sebelumnya yang dilakukan oleh Murkherjee \& Nath (2007) yang menjelaskan bahwa privasi yang ketat akan menimbulkan peran kepercayaan yang berpengaruh secara positif terhadap pembelian secara online dan Hasil ini sejalan dengan penelitian sebelumnya yaitu menurut Anwar dan Adidarma (2016) menjelaskan bahwa kepercayaan dapat memediasi privasi secara positif pada minat beli secara online. Hal ini bersangkutan dengan keamanan pada privasi pelanggan akan meningkatkan kepercayaan untuk membeli suatu produk pada situs pembelanjaan online.

\section{KESIMPULAN DAN SARAN}

a. Privacy berpengaruh positif dan signifikan terhadap trust pada pelanggan Shopee di Jakarta. Hal ini menjelaskan bahwa tingginya keamanan privacy akan meningkatkan rasa kepercayaan (trust) pada pelanggan Shopee di Jakarta.

b. Social Influence berpengaruh positif secara signifikan terhadap online purchase intention pada pelanggan Shopee di Jakarta. Hal ini menjelaskan bahwa peningkatan pengaruh sosial akan meningkatkan niat pembelian secara online pada pelanggan Shopee di Jakarta

c. Trust dapat memediasi privacy positif secara signifikan terhadap online purchase intention pada pelanggan Shopee di Jakarta. Hal ini menjelaskan bahwa kepercayaan yang kuat pada keamanan privasi akan meningkatkan niat pembelian secara online pada pelanggan Shopee di Jakarta.

Berdasarkan penelitian ini, terdapat beberapa saran yaitu perusahaan Shopee harus mempertahankan pelanggan yang sudah ada dengan meningkatkan keamanan pada proses transaksi dan privasi pelanggan agar meningkatkan kepercayaan pelanggan pada Shopee sehingga pelanggan akan terus meningkat dengan seiring waktu, Shopee harus meningkatkan performa dalam aplikasi agar Shopee tetap terjaga nama baiknya agar pengaruh sosial dapat merekomendasikan lingkungan untuk berelanja menggunakan Shopee sehingga tidak ada lagi kekhawatiran pada pelangaan saat bertransaksi secara online atau memberikan privasi.Untuk peneliti selanjutnya, diharapkan dapat memperluas jumlah sampel yang dapat digunakan dan menyiapkan jangka waktu yang lebih lama agar dapat memberikan hasil yang lebih optimal 
dengan kondisi yang terjadi sebelumnya dan diharapkan dapat menggunakan variabel-variabel independen yang lain selain privacy, social influence dan trust sebagai variabel mediasi agar memiliki penelitian yang lebih luas terhadap online purchase intention pada pelanggan Shopee di Jakarta.

\section{Ucapan Terima Kasih (Acknowledgement)}

Terima kasih kami ucapkan pada Lembaga Penelitian dan Pengabdian kepada Masyarakat Universitas Tarumanagara yang telah memberikan pendanaan dalam penelitian ini melalui skema Hibah Penugasan Tugas Akhir Skripsi.

\section{REFERENSI}

Akroush, Mamoun N dan Mutaz M. Al-Debei. 2015. "An integrated model of factors affecting consumer attitudes towards online shopping". Business Process Management Journal, Vol. 21 No. 6, hal. 1353-1376

Amin, H. (2007). Extending TAM to SMS banking: analyzing the gender gap among students.International Journal of Business and Society, Vol. 8 No. 1, pp. 24-45.

Anwar, Rosian, Adidarma Wijaya. 2016. Pengaruh Kepercayaan Dan Risiko Pada Minat Beli Belanja Online. Jurnal Manajemen dan Bisnis Sriwijaya. 14 (2),pp : 156-168

Belanger, France et al. (2002). Trustworthiness in Electronic Commerce: The Role of Privacy, Security, and Site Attributes. Journal of Strategic Information 100 Systems 11. (Online), USA.

Bertrandias, L. and Elgaaied-Gambier, L. (2014). Others' environmental concern as a social determinant of green buying. Journal of Consumer Marketing, Vol. 31 Nos 6/7, pp. 417429.

Bianchi, C., \& Andrews, L. (2012). Risk, Trust, and consumer online purchasing behaviour: A Chilean perspective. International Marketing Review, 29(3), 253-275.

Chen, Y.-H. and Barnes, S. (2007), Initial trust and online buyer behavior. Industrial Management and Data Systems. Vol. 107 No. 1, pp. 21-36.

Chen, Y., Yan, X., Fan, W., \& Gordon, M. (2015). The joint moderating role of trust propensity and gender on consumers' online shopping behavior. Computers in Human Behavior, 43, 272-283.

Chiu, C.M., Chang, C.C., Cheng, H.L. and Fang, Y.H. (2009). Determinants of customer repurchase intention in online shopping. Online Information Review, Vol. 33 No. 4, pp. 761-84.

Clemons, E. K., Wilson, J., Matt, C., Hess, T., Ren, F., Jin, F., \& Koh, N. S. (2016). Global differences in online shopping behavior: understanding factors leading to trust. Journal of Management Information Systems, 33(4), 1117-1148.

Delia, Vazquez., Xingang Xu., (2009). Investigating linkages between online purchase behavior variables. International Journal of Retail \& Distribution Management, Vol. 37 Iss: 5, pp. 408-419.

Delre, S.A., Jager, W., Bijmolt, T.H. and Janssen, M.A. (2010). Will it spread or not? The effects of social influences and network topology on innovation diffusion. Journal of Product Innovation Management, Vol. 27 No. 2, pp. 267-282.

Eisingerich, Andreas B. and Simon J. Bell (2007). Maintaining customer relationships in high credence services. Journal of Services Marketing, 21(4), 253-62.

Han, P. and Maclaurin, A. (2002). Do consumers really care about online privacy?. Marketing Management, Vol. 11 No. 1, pp. 35-38. 
Husnain, A., Din, S. M. U., Hussain, G., \& Ghayor, Y. (2017). Estimating Market Trends By Clustering Social Media Reviews. 13th International Conference on Emerging Technologies (ICET), 1-6.

Liu, A. F., Xiao, B. S., Lim, E. T. K., \& Tan, C. W. (2017). The Art of Appeal in Electronic Commerce: Understanding the Impact of Product and Website Quality on Online Purchases. Internet Research, 27(4), 752-771.

Lin, H.H., Yen, W.C., Wang, Y.S., \& Yeh, Y.M. (2018). Investigating consumer responses to online group buying service failures: The moderating effects of seller offering type. Internet Research, 28(4), 965-987.

Mukherjee, A. and Nath, P. (2007). Role of electronic trust in online retailing: a re-examination of the commitment-trust theory. European Journal of Marketing, Vol. 41 Nos 9/10, pp. 1173-202.

Poddar, Amit \& Donthu, Naveen \& Wei, Yujie, 2009. Web site customer orientations, Web site quality, and purchase intentions: The role of Web site personality. Journal of Business Research, Elsevier, vol. 62(4), pages 441-450.

Rosetta. (2014). Customer Engagement from the Customer's Perspective. Rosetta Consulting. (Available at http://www.rosetta.com/ 9-12- 2016).

Siedlecki, K. L., Salthouse, T. A., Oishi, S., and Jeswani, S. (2014). The relationship between social support and subjective well-being across age. Social Indicators Res. 117, 561- 576.

Venkatesh, V., Morris, M.G., Davis, G.B. and Davis, F.D. (2003). User acceptance of information technology: toward a unified view.MIS Quarterly, Vol. 27 No. 3, pp. 1-54.

Wu, K. , Huang, S.Y. , Yen, D.C. and Popova, I. (2012). He effect of online privacy policy on consumer privacy concern and trust. Computers in Human Behavior, Vol. 28 No. 3, pp. 889-897. 